\title{
MELAKSANAKAN HAK-HAK ANAK DALAM PERSPEKTIF ISLAM SEBAGAI UPAYA PENDIDIKAN AGAMA PADA ANAK
}

\author{
Oleh: \\ Santi Lisawati \\ Fakultas Agama Islam Universitas Ibn Khaldun Bogor \\ santilisnawati@gmail.com
}

\begin{abstract}
Abstrak
Anak memiliki keistimewaan tersendiri. Ajaran Islam memiliki kesempurnaan dalam memberikan hak-hak terhadap anak. Hak-hak anak memiliki cakupan yang luas dan unik. Merujuk kepada sumber ajaran yaitu Quran dan Hadits. Pada Quran terdapat sumber ajaran yang hakiki dan tidak terbantahkan, dari yang Maha Memahami akan apa yang diciptakan-Nya. Serta sumber ajaran hadis, dari segenap perilaku sosok yang dianggap sebagai Quran berjalan. Melaksanakan hak-hak pada anak menjadi bagian dalam pendidikan agama pada anak. Dari keluasan hak anak dalam Islam, secara garis besar dapat dikatagorikan; 1) hak anak sebelum dilahirkan dan 2) hak anak saat dilahirkan. Sebelum anak dilahirkan, maka anak berhak untuk mendapat perlakuan dari calon ayah atau ibunya dengan jalan, ayah memilihkan ibu yang baik dan begitu juga ibu, memilih pasangan yang baik yang kelak akan menjadi ayah dari anak yang dikandungnya. Saat anak dilahirkan maka sejumlah hak anak dalam ajaran Islam telah dicontohkan Rasulullah Saw serta diisyaratkan dalam Quran. Di antara hak anak saat dilahirkan yaitu; disunnahkan membaca azan dan iqomat di telinga bayi, memberi nama yang baik, pentingnya pemberian ASI, nutrisi dari nafkah yang halal dan baik, metahnik bayi, mencukur rambut, melaksanakan aqiqah, khitan, dan memberikan pendidikan dan mengembangkan potensi sesuai dengan fase-fase perkembanganya.
\end{abstract}

Kata Kunci: Pendidikan Islam,Hak-Hak Anak, Quran dan Hadits

\section{Pendahuluan}

Anak lahir tidak berdaya, keberadaan orangtua dan orang dewasa memberikan hak yang semestinya didapatkan anak. Hak anak adalah sesuatu yang sepatutnya didapatkan anak. Islam mengajarkan bagaimana anak semestinya mendapat perlakuan. Ajaran Islam bersumber dari Qur'an dan hadits. Al-qur'an sebagai pedoman, sumber hukum, sumber ilmu pengetahuan dan petunjuk bagi manusia. Al-Qur'an mengatur ruang kehidupan manusia, agar manusia tidak tersesat dan mendapatkan kebahagian.

Begitu pula dengan Hadist yang merupakan perkataan, perbuatan, tingkah laku, dan taqrir yang disandarkan kepada Nabi Muhammad SAW, yang tentunya hadis-hadis yang dapat dipegang kebenarannya dan dapat dijadikan hujjah. Karena itu Al-Qur'an dan hadist merupakan sumber ilmu dan petunjuk bagi umat manusia. Apabila manusia berpegang pada keduanya kelak manusia tidak akan tersesat. Sebagaimana sabda Rasulullah Saw, 
"Aku tinggalkan kepadamu dua perkara yang kalian tidak akan tersesat selamanya apabila berpegang teguh kepada dua hal tersebut yaitu Al-Qur'an dan As-Sunnahku." (HR.Muslim.)

Bila kita menelusuri pembahasan isi Al-Qur'an dan hadist, maka kita akan mendapatkan dan menyadari betapa besar perhatian dan perlindungan terhadap perkembangan anak. Anak adalah bagian dari keluarga dan masyarakat. Anak juga penerus dan pembentukkan wajah masa depan, jika anak sebagai individu tumbuh berkembang dan memiliki akhlak yang baik, maka kondisi masyarakat secara umum akan membaik.

Anak merupakan pewaris yang memakmurkan Ibu pertiwi, pasukan yang siap melindungi tanah tumpah darah dari serangan dan rorongan musuh, dan anak adalah ilmuan yang menebarkan cahaya ilmu pengetahuan keselurah penjuru negeri. Anak juga merupakan ibu masa depan yang siap mencerdaskan putra-putri bangsa hingga menjadi tokoh-tokoh yang handal diberbagai bidang kehidupan.

Karena itu Islam sangat menjungjung tinggi hak-hak anak, sejak anak dalam rahim seorang ibu. Bahkan lebih jauh dari itu, yaitu sebelum pasangan suami-istri bertemu. Karenanya Islampun menganjurkan wanita untuk memilih suami yang menjungjung tinggi agamanya, begitupula laki-laki jangan tergoda dengan penampilan fisik semata tetapi jauh lebih penting dari itu adalah agar memilih istri yang menjungjung tinggi agamanya.

Dalam Al-Qur'an kita dapat mengetahui bagaimana perilaku kaum jahiliyah terhadap anak-anak mereka sebagaimana yang terdapat dala QS. An-Nahl ayat 58-59.

"dan apabila seorang mereka diberi kabar dengan kelahiran anak perempuan, hitamlah (merah padam) mukanya, dan dia sangat marah. Dia menyembunyikan dirinya dari orang banyak disebabkan buruknya berita yang disampaikan kepadanya. Apakah dia akan memeliharanya dengan menaggung kehinaan ataukah akan menguburnya ke dalam tanah hidup-hidup ? ketahuilah alangkah buruknya apa yang mereka tetapkan itu." (QS, An-Nahl, 16:58-59).

Padahal Allah SWT mengganjurkan kita untuk menerima pemberian-Nya berupa anak dengan senang hati tanpa membeda-bedakan antara laki-laki dan perempuan.

"Kepunyaan Allahlah kerajaan langit dan bumi. Dia menciptkan apa yang dia kehendaki. Dia memberikan anak-anak perempuan kepada siapa saja yang 
dikehendaki, dan memberikan anak-anak laki-laki kepada siapa saja yang dikehendaki. Dia menganugrahkan kedua jenis laki-laki dan perempuan kepada siapa yang dikehendaki-Nya. Dan dia menjadikan mandul bagi siapa yang dia kehendaki. Sesungguhnya Dia Maha Mengetahui lagi Maha Kuasa.” (QS. Asy-syura, 49-50).

Ketika anak manusia dilahirkan, kondisinya sangat tidak berdaya, bisa jadi merupakan makhluk hidup yang paling lemah ketika baru dilahirkan dibandingkan dengan makluk ciptaan Allah yang lain seperti binatang. Anak ayam misalnya baru menetas beberapa jam kemudian sudah bisa berjalan. Anak manusia yang dilahirkan sangat lemah sekali perlu bantuan dan ketergantungan orang-orang yang terdekat dengannya yaitu orang tua.

Ketidakberdayaan anak yang baru lahir dalam psikologi perkembangan dikatakan karena belum berkembangnya keadaan tubuh dan sistem syaraf. Menurut Hurlock (2003) ketidakberdayaan bayi dikarenakan bebrapa hal diantaranya: (a) ketidakmampuan untuk memepertahankan homeostatis, (b) ketidakmampuan untuk mengendalikan kegiatan motorik, (c) ketidak mampuan untuk berkomunikasi, (d) keadaan organ indra yang belum berkembang dan (e) ketidakmampuan untuk belajar. ${ }^{1}$

Ketidakberdayaan bayi tersebut di atas sebagai modal dalam jalan pembinaan atau pendidikan agar bayi tumbuh dan berkembang menjadi manusia dewasa dan mandiri. Dalam hal ini perlakuan orang tua yang efektif dan kondusif dapat membantu perkembangan anak, secara eksplisit Qur'an maupuan Hadist Rasulullah SAW sangat memperhatikan anak-anak. Anak memiliki hak-hak yang harus dipenuhi.

Tulisan ini membahas tentang hak-hak anak menurut Islam, tentu bersumber kepada Qur'an dan Hadist, yaitu apakah hak-hak anak yang selayaknya didapatkan oleh anak menurut perspektif Islam.

\section{Pembahasan}

\section{Hakekat Hak Anak}

Pengertian anak, dapat merujuk ada berbagai dimensi. Dalam dimensi perkembangan anak memiliki batas rentngan usia yang umum yaitu usia sejak kelahiran yaitu nol tahun hingga usia sekolah dasar yaitu usia 12 tahun. Ini yang disebut masa

1 Elizabeth B. Hurlock, Perkembangan Anak, Terjemahan Med Meitasari Tjandrasa \& Muslichah Zarkasih. (Jakarta: Erlangga, 2005), h. 16. 
anak-anak, berakhir diusia 12 tahun. Selanjutnya dikenal dengan istilah masa remaja yang berakhir diusia 18-21 tahun.

Hal ini bisa dilihat dalam masa perkembangan yang dikemukakan Soetjiningsih yaitu: a. perkembangan pra-lahir (mulai masa konsepsidan berlangsung \pm 280 hari), b. masa bayi (0-2 tahun), c. masa anak (2-12 tahun) dibagi menjadi masa anak awal (2-6 tahun) dan masa anak akhir (6-12 tahun) dan d. masa remaja (12-21 tahun) dibagi menjadi tiga masa remaja awal (12-15 tahun), masa remaja tengah (15-18 tahun), dan masa remaja khir (18-21 tahun). ${ }^{2}$ Pengertian anak yang di setujui dalam konvensi PBB adalah bahwa yang dikatakan anak adalah yang berusia di bawah delapan belas tahun. ${ }^{3}$

Dalam ajaran Islam, anak beriring dengan perkembangan dan tanggung jawab. Sebelum memasuki usia baligh, anak belum memikul tanggung jawab. Sedangkan masa baligh memiliki ciri yang khas, baik pada laki-laki maupun perempuan. Anak atau AthThifl dalam persepsi ajaran Islam adalah usia bayi hingga akil baligh. ${ }^{4}$ Dalam masa ini anak berada dalam tanggung jawab orangtua, saat baligh anak sudah mempertanggjawabkan akan kewajiban amal ibadah dengan sendirinya.

Karena itu ada sejumlah hak anak yang mesti diberikan pada masa anak. Hakhak anak memiliki ragam bentuk, namun pada hakekatnya adalah hak yang melekat dalam keberlangsungan hidup anak. Dalam perspektif konvensi perserikatan BangsaBangsa, bahwa terdapat sejumlah hak-ahak anak, yang intinya melindung dan mengantarkan kepada kehidupan anak yang lebih baik. Sejumlah hak anak menurut rumusan konvensi PBB antara lain sebagai berikut: a. Berhak mendapat perlindungan dan perawatan, b. Saat lahir anak berhak atas nama, kebangsaan dan pengasuhan, c. Anak berhak mengumukakan secara bebas pandangannya dan didengar, d. Kebebasan berpikir, berhati nurani dan beragama, e.Kebebasan untuk berhimpun, dan berkumpul secara damai, 6)Hak atas kesehatan ${ }^{5}$

Dalam capaian akhir masa anak yang berbeda antara tinjauan perkembangan, undang-undang dan juga agama, namun sejumlah hak anak dalam Islam memiliki orientasi yang jauh sebelum anak itu lahir. Mempersipkan dan memilih pasangan yang

${ }^{2}$ Christiana Hari Soetjiningsih, Perkembangan Anak (Jakarta: Prenada, 2012), h. 22.

3 Konvensi Hak-Hak Anak, www.unicef.org/magic/media/.../CRC bahasa indonesia version.pdf (diakses 20.10.2014).

${ }^{4}$ Sulaimn A. Ubydat, dalam Hidayatul Ahmad, Ensiklopedi Pendidikan Anak, Terj. Sari Narulita \& Umron Jayadi (Jakarta: Fikr, 2006), h. 17.

5 Konvensi Hak-Hak Anak, www.unicef.org/magic/media/.../CRC bahasa indonesia version .pdf (diakses 20.10.2014). 
melahirkan generasi atau anak menjadi bagian dari hak anak dalam Islam. Cakupan yang luas akan hak anak dalam Islam, secara garis besar dikategorikan menjadi: 1) sebelum anak dilahirkan, dan 2) saat anak dilahirkan. ${ }^{6}$ Keluasan hak anak dalam islam memberikan petunjuk bahwa Islam sangat melindungi dan memuliakan anak.

\section{Makna Kehadiran Anak}

Ada beberapa ayat Al-Qur'an dan Hadist yang membicarakan atau terkait dengan masalah anak, yang kesemuanya menekankan pentingnya rasa cinta dan kasing sayang. Mengenai kehadiran anak dalam sebuah rumah tangga menurut perspektif AlQur'an dan Hadist dapat disimpulkan sebagai berikut:

a. Anak merupakan karunia serta nikmat dari Allah yang harus disyukuri, Allah berfirman:

“.....dan kami membantu dengan harta kekayaan dan anak-anak dan kami jadikan kamu kelompok yang lebih besar" (QS. Al isra :6).

b. Anak merupakan perhiasan kehidupan dunia. Firman Allah:

“.... harta dan anak-anak adalah merupakan perhiasaan kehidupan dunia..." (QS.Al Kahfi :46).

c. Kehadiran anak merupakan peristiwa yang membahagiakan (kabar gembira).

“ hai zakariya, sesungguhnya kami memberi kabar gembira kepadamu akan (beroleh) seorang anak yang bernama yahya, yang sebelumnya belum pernah kami menciptakan yang serupa dengan dia.” (QS. Mariyam : 7).

d. Anak dalam rumah tangga menjadi penyejuk hati dan penenang jiwa. Allah berfirman :

“... ya Tuhan Kami, anugrahkanlah kepada kami, istri-istri kami dan anak-anak kami sebagai penyenang hati...” (QS. Al furqan :74)

"dan kami beri dia (Ibrahim) kabar gembira dengam seorang anak yang amat sabar." (QS. As saffat : 101)

e. Anak adalah bagian dari sumber kebajiakan dan kemanfaatan bagi orang tuanya baik ketika masih hidup maupun sudah meninggal.

“ada seorang hamba yang derajatnya diangkat ke tingkat yang lebih tinggi. Lalu dia berkata :"Ya Tuhan, kenapa derajatku diangkat menjadi lebih tinggi seperti ini?"

\footnotetext{
${ }^{6}$ Hidayatul Ahmad, Ensiklopedi Pendidikan Anak, Terj. Sari Narulita \& Umron Jayadi (Jakarta: Fikr, 2006), h. 27.
} 
kemudian Allah berfirman: "ini berkat istigfar yang selalu dimohonkan oleh anakmu sepeninggalmu. “(HR, Ahmad \& Baihaq)

"Apabila manusia meninggal, maka terputuslah semua amalnya, kecuali tiga perkara : shadaqah jariyah, ilmu yang bermanfaat, dan anak shalih yang senantiasa mendoakan orang tuanya." (HR. Muslim)

f. Anak sebagai pengundang Rahmat

“ Andaikan bukan karena anak-anak yang sedang menyusu, orang-orang tua yang rajin ruku', dan binatang-binatang yang masih merumput, niscaya siksaan sudah benar-benar diturunkan kepada kalian semua." ( HR. Baihaqi dan khatib, dari Abu Hurairoh ra)

Demikian Quran dan Hadits memerikan gambaran tentang bagaimana kedudukan, kemuliaan dan pandangan terhadap anak. Anak adalah karunia Allah yang keberadaannya membutuhkan bimbingan dan didikkan orangtua. Namun demikian anak pun dapat menjadi ujian dan fitnah bagi orangtua. meski pun anak teramat berharga bagi orangtua, kecintaan kepada Allah dan Rasul tetaplah di atas kecintaan terhadap anak.

\section{Hak Anak dalam Perspektif Islam}

Anak memiliki sejumlah hak yang patut dipenuhi oleh orangtua. adapun beberapa hak anak di antaranya adalah:

a. Memilihkan calon ibu atau ayah baik

Bibit yang baik akan melahirkan kualitas yang baik, ibarat orang menanam pohon maka perlu memilih tempat yang subur dan bagus. Sabda Rasul saw :

"Pilihlah wanita yang terbaik untuk menitipkan spermamu, karena sesungguhnya akhlak seorang ayah akan menurun kepada anaknya. Dan pilihlah wanita yang terbaik demi spermamu dan nikahilah wanita yang sepadan. " ( HR. Ibnu Majah, Baihaqi Hakim).

"Wanita dinikahi karena empat hal: karena hartanya, kebangsawanannya, kecantikannya dan karena agamanya. Untuk itu carilah wanita yang taat beragama, niscaya engkau akan bahagia."(HR. Bukhari Muslim.)

“Janganlah kamu menikahi wanita kerena kecantikannya. Sebab boleh jadi kecantikan itu membuat mereka durhaka. Janganlah menikahi wanita karena hartanya. Sebab boleh jadi harta kekayaan membuat mereka melampaui batas, karena itu nikahilah wanita karena agamanya. Sebab sesungguhnya wanita budak berkulit hitam 
yang taat beragama justru lebih baik untuk dinikahi daripada wanita cantik lagi berharta yang tidak taat beragam."(HR. Ibnu Majah).

"Nikahilah oleh kamu sekalian wanita yang kalian cintai, yang berketurunan yang banyak. Sesungguhnya aku bangga jika umatku banyak pada hari kiamata nanti. “ (HR. Ahmad dan ibn hibban)

Hadits di atas menggambarkan bagaimana sebaiknya para lelaki memilih wanita yang hendak dinikahinya. Namun demikian wanita pun memiliki perintah yang untuk memilih lelaki yang baik yang hendak menjadi pasangan dalam hidupnya dan melahirkan generasi sebagai amanah.

b. Menjaga dan merawat janin dalam kandungan

Al Qur'an secara normatif telah meberikan isyarat kepada para ibu untuk melakukan tugas yang qodrati yaitu mengandung, melahirkan dan meyusui. Firman Allah SWT,

"Ibunya telah mengandungnya dalam keadaan lemah yang bertambah-tambah dan menyapihnya dalam 2 tahun. “(QS.31:41).

"Ibunya mengandungnya dengan susah payah, dan melahirkannya dengan susah payah pula, mengandungnya dan menyapihnya adalah tiga puluh bulan. (QS. 46:15).

Pada masa kehamilan, proses pembentukan kepribadian anak telah dimulai bahkan jauh sebelum itu yaitu pada tahap konsepsi. Seorang ibu telah dapat memberikan pengaruh-pengaruh fisik dan psikologi, dengan memberikan rasa nyaman, tenang, kasih sayang dan nutrisi yang diperlukan. Terdapat bukti bahwa music dapat memberikan ketenangan pikiran dan tubuh. Musik "mengorganisasikan" pola-pola neuron di seluruh otak, terutama pola-pola yang berkaitan dengan pemikiran kreatif. ${ }^{7}$

Dalam hal ini yang tak kalah penting bagi para ibu dalam memberikan ketenangan pada ibu dan bayi dengan cara memperdengarkan ayat-ayat Al-Qur'an. Disamping sebagai dzikrullah, agar hati menjadi tenang, sehingga membuat bayi merasa nyaman. Hal tersebut juga merupakan langkah pendidikan keagamaan pada masa bayi, melindungi diri dan janin dalam kandungan agar terhindar dari godaan syetan.

\footnotetext{
${ }^{7}$ Jalaudin Rakhmat, Belajar Cerdas, (Bandung: MLC, 2005), h. 214.
} 
c. Ketika bayi lahir maka disunnahkan membaca azan ditelinga bayi

Saat anak lahir ke dunia, suara dan kalimat pertama didengarkan adalah kalimat Tauhid. Kalimat yang mengandung kebaikan, sebagai pendidikan dan pemeliharaan awal dari godaan syetan. Karena itu Rasulullah bersabda.

"Barangsiapa telah melahirkan seorang bayi, maka hendaknya ia mengazani bayi itu pada telinganya yang kanan, dan diiqomahkan pada telinganya yang kiri, niscaya uтmu shibyan (jin atau syetan) tidak akan mengganggunya”.(HR. Ibnu Sunni dari Hasan bin Ali ra).

d. Pentingnya pemberian ASI, Nutrisi/Nafkah yang halal dan baik.

ASI adalah makanan dan minuman yang paling utama bagi para bayi. Tidak ada manusia yang sanggup memproduksi susu buatan atau susu formula yang sama kualitasnya dengan ASI. ASI merupakan pemberian Allah SWT kepada seluruh anak manusia, untuk menjamin kesehatan ibu dan anak, serta menjamin kelangsungan hidup anak manusia itu kelak dikemudian hari.

Sementara sudah banyak hasil riset yang dilakukan oleh pakar kesehatan dunia yang menyatakan bahwa, anak-anak yang pada masa bayinya menerima ASI, akan jauh lebih cerdas, lebih sehat dan kuat ketimbang anak-anak yang pada masa bayinya menerima susu industri atau susu kaleng, sedangkan ASI yang sangat berpengaruh terhadap kecerdasaan dan ketahanan tubuh adalah ASI eksklusif, yaitu pemberian ASI yang tidak dicampur dengan makanan lainnya. Di indonesia pemberian ASI eksklusif disarankan 4 bulan, namun baru-baru ini WHO merekomendasikan bahwa bayi diberi ASI eksklusif selama 6 bulan, untuk lebih meningkatkan daya tahan tubuh/kesehatan. Di enam bulan pertama pemenuhan kebutuhan gizi cukup melalui pemberian ASI eksklusif. $^{8}$

Namun jauh sebelum itu dalam QS Al-Baqarah ,2:233 Allah berfirman :

"Para ibu hendaklah menyusukan anak-anaknya selama dua tahun penuh, yaitu bagi yang ingin menyempurnakan penyusuannya" (QS. 2:233).

Cara Islam dalam merawat dan menyusukan anak merupakan cara terbaik dalam upaya pendidikan anak.

\footnotetext{
${ }^{8}$ Indra Kusumah dan Vindhy Fitrianti, The Excellent Parenting (Yogyakarta: Qudsi Media, 2012), h. 96.
} 
e. Metahnik Bayi

Mentahnik yaitu menguyahkan makanan pertama sekali, kemudian memasukan hasil kunyahan itu kedalam mulut bayi yang baru lahir sambil berdoa agar ia mendapatkan berkah dari Allah Swt.

Sebagaimana yang dikisahkan oleh Asma' binti Abu Bakar RA, berkata “ketika aku mengandung Abdullah bin Zubair di Mekkah, aku pergi ke Madinah dan akan berhenti di Quba, lalu beliau meletakkan bayi itu dipangkuannya, kemudian beliau meminta dibawakan kurma, lalu dikunyanya dan dimasukan ke mulut bayi itu. Maka yang pertama-tama masuk kemulutnya adalah air liur Rasulullah saw, kemudian dikunyahnya kurma, lalu beliau berdoa dan memohon berkah baginya." (HR. Muslim dari Asma’ bin Abi Bakar ra).

f. Mencukur rambut

Pendidikan akan nilai kebersihan dan juga shadaqah diajarkan pada awal kehidupan anak. Dengan melalui perintah mencukur rambut bayi.

"Rasulullah saw pernah memerintahkan untuk mencukur kepala hasan dan husain pada hari ketujuh dari kelahirannya. Setelah keduanya dicukur, lalu disedekahkanlah perak seberat timbangan rambutnya." (HR Yahya bin Bakir dari Anas bin Malik ra..)

Terdapat hikmah yang terkandung dalam mencukur rambut, di antaranya adalah aspek kebersihan, sebab rambut yang dibawa atau tumbuh sejak dalam kandungan melewati lubang yang kotor seperti darah nifas setelah melahirkan, sehingga perlu diberishkan dan dicukur agar merangsang pertumbuhan rambut yang baru dan lebih bagus, aspek kesehatan akan merangsang ketajaman fungsi pendengaran, panca indra dan otak. Disamping itu pula aspek keagamaan rasa syukur, sang bayi belajar berkorban dengan bersedekah emas/perak seberat rambut yang dicukur.

g. Memberi nama yang baik

Berbeda dengan William Shakepiere, yang mengatakan What is a name? apalah arti sebuah nama. Bagi kita sebagai muslim, nama memiliki arti yang sangat penting. Karena itu Rasulullah saw, mengatakan:

"Sesungguhnya kalian akan dipanggil pada hari kiamat dengan menyebut nama-nama kalian dan nama-nama ayah kalian, maka oleh karena itu perbaikilah nama-nama kalian." (HR. Abu Dawud dari Abu Darda ra). 
Nama-nama yang baik, benar dan indah adalah nama-nama yang Allah senangi, yaitu nama-nama dengan menggunakan nama-nama-NYA yang indah seperti Abdullah (hamba Allah), Abdur Rahman (hamba yang pengasih), sebagaimana sabda Nabi SAW : "Berilah nama anak-anak kalian dengan nama-nama Nabi dan nama-nama yang paling disenangi oleh Allah ta'ala, yaitu Abdullah dan Abdurrahman, yang paling benar ialah harits (yang rajin bekerja) dan hammam (yang tinggi cita-citanya) dan yang paling buruk adalah Harb (perang) dan murrah (pahit)." (HR. Abu Daud, An Nasai dari Abu Wuhaib Al jasymi ash Shahabi ra).

Nama yang baik dan indah belumlah cukup menjadikan anak yang baik, namun lebih jauh dari itu adalah bagaimana membesarkan dan mendidik anak dengan cara yang Islami, sebab tak sedikit nama yang baik dan indah seperti Muhammad Hasan, Abdullah tetapi perilakunya tidak mencerminkan namanya. Namun paling tidak kita berupaya untuk memberikan yang terbaik dengan memulai nama yang baik sebagai doa. Setiap kali orangtua mengucapkannya itulah doa yang diharapkan bagi anaknya.

h. Aqiqah

Menyembelih hewan pada hari ketujuh dan mencukur rambut bayi adalah hal yang dilakukan saat aqiqah. Rasul bersabda:

'Aqiqah itu dilaksanakan karena kelahiran seorang bayi, maka sembelihlah hewan dan jauhkanlah segala gangguan darinya” (HR. Bukhari).

"Bagi anak laki-laki dua ekor kambing yang sama umurnya dan hampir mirip bentuknya, sedangkan untuk anak perempuan satu ekor kambing. "(HR. Ahmad, Turmudzi dari Aisyah ra).

i. Khitan

Secara bahasa berarti memotong kulup (kulit) di atas kepala zakar, sedangkan secara istilah memotong kulit yang ada di sekitar ujung zakar atau batas pergelangan zakar yang sudah ditentukan oleh hukun syara'. Rasulullah bersabda:

"Fitrah itu ada llima : khitan, mencukur bulu sekitar kemaluan, memotong kumis, memotong kuku dan mencabut bulu ketiak." (HR. Bukhari dan muslim dari Abi Hurairoh).

j. Pendidikan dan mengembangkan potensi sesuai dengan fase-fasenya

Di antara faktor-faktor yang berpengaruh dalam membentuk kepribadian anak adalah faktor lingkungan. Yang dimaksud faktor lingkungan menurut Kihajar 
Dewantara seorang tokoh pendidikan, yaitu lingkungan rumah tangga, lingkungan sekolah dan lingkungan masyarakat. Namun yang paling banyak dan berpengaruh saat masa bayi dan anak adalah pendidikan di lingkungan rumah tangga dimana orang tua sebagai figure sentral yang sangat berpengaruh bagi anak.

Ada beberapa Hadits Rasul saw yang berkenaan dengan pentingnya pendidikan, yaitu :

"Tuntunlah bayi-bayi kalian pada berbicara dengan perkataan la ilaha illallah (Tiada Tuhan yang pantas disembah selain Allah), dan tuntunlah mereka ketika meninggal dengan perkataan La ilaha illallah pula." (HR. Hakim).

Karena itu Rasulullah mengajari cucunya dengan pendengaran pertama yaitu adzan, yang di dalamnya terdapat kata La illaha illallah.

"Didiklah anak-anak kalian dengan tiga perkara: mencintai Nabi kalian, mencintai ahli baitnya dan senang membaca Al-Qur'an."(HR. Tabrani).

"Didiklah anak-anak kalian dengan memanah, berenang dan naik kuda." (HR. Dawud).

"Perintahkanlah anak-anak kalian melakukan shalat ketika berumur tujuh tahun, dan pukullah mereka (jika masih meninggalkan) kalau sudah berumur sepuluh tahun, dan pisahkanlah diantara mereka tempat tidurnya."(HR, Abu Daud, Tirmidzi).

Pendidikan yang melibatkan seluruh potensi anak meliputi jiwa dan raga sangat diperhatikan sejak kelahiran. Tidak hanya sehat secara fisik, namun juga sehat sehara rohani. Dengan menanamkan tauhid yang kokoh, pekerti yang baik dan fisik yang kuat diharapkan anak menemukan kebahagiaan di dunia dan dikehidupan yang abadi di akhir nanti.

\section{Kesimpulan}

Umat Islam memiliki pedoman hidup yang menjamin kebahagiaan di dunia juga di akhirat. Rasulullah Saw telah mewariskan Qur'an dan Hadits sebagai pegangan seorang Muslim. Begitu pula dengan bagaimana memperlakukan anak, Islam telah memberikan gambaran yang lengkap di dalamnya. Anak terlahir ke dunia dimaknai sebagai sebuah anugerah Allah untuk selanjutnya diberi pendidikan agar menjadi anak yang sholeh yang kelak akan memberikan kebermanfaatan kepada orangtua dan sesama. Terdapat hak-hak anak yang sepatutnya dipenuhi oleh orang tua, berdasarkan Qur'an dan hadits sebagai jalan pendidikan agama bagi anak. Di antara hak-hak anak itu adalah: 1) memilihkan calon ibu atau ayah baik, 2) menjaga dan merawat janin dalam 
kandungan, 3) ketika bayi lahir maka disunnahkan membaca azan da iqomat di telinga bayi, 4) pentingnya pemberian ASI, nutrisi/nafkah yang halal dan baik, 5) metahnik bayi, 6) mencukur rambut, 7) memberi nama yang baik, 8) melaksanakan aqiqah, 9) khitan, dan 10) pendidikan, dan mengembangkan potensi sesuai dengan fase-fasenya.[]

\section{Daftar Pustaka}

Ahmad, Hidayatul (2006). Ensiklopedi Pendidikan Anak, Terj. Sari Narulita \& Umron Jayadi. Jakarta: Fikr.

Al-amir, Najib Khailid (1990). Tarbiyah Rasulullah, Jakarta: Gema Insani.

Al-Qur'an dan terjemah (2012). Penerbit: Cordoba International-Indonesia.

Darajadjat, Zakiyah (1991). Ilmu Jiwa Agama. Jakarta: Bulan Bintang.

Hadian, Abu (2003). Hak-Hak anak dalam syariat Islam, Jakarta: Al-manar.

Hurlock, Elizabeth B (2005). Perkembangan Anak. Terjemahan Med Meitasari Tjandrasa \& Muslichah Zarkasih. Jakarta: Erlangga.

Kusumah, Indra dan Vindhy Fitrianti (2012). The Excellent Parenting. Yogyakarta: Qudsi Media.

Rakhmat, Jalaudin (2005). Belajar Cerdas. Bandung: MLC.

Soetjiningsih, Christiana Hari (2012). Perkembangan Anak. Jakarta: Prenada.

Ulwan, Abdullah Nashih (2013). Tarbiyah al-aulad fi islam (terj). Jakarta: Khatulistiwa.

Konvensihakhakanak.www.unicef.org/magic/media/.../CRC_bahasa_indonesia_versio n.pdf(diakses20.10.2014) 